\title{
Research on the Micro Class Teaching Application of the University Computer Foundation Course
}

\author{
Nan $X i e^{1, a^{*}}$ \\ ${ }^{1}$ Zhejiang University of Water Resources and Electric Power, Hangzhou, China \\ a905321899@qq.com
}

\begin{abstract}
Keywords: Micro class; University computer foundation; Teaching application
\end{abstract}
\begin{abstract}
With the rising of micro class teaching mode, micro class teaching of the practical courses bring great convenience to teachers. this paper applied undergraduate college non-computer professional courses of "University Computer Foundation" as an example, and it has described the micro class in the application strategy of university computer foundation curriculum, focusing on analyzing the micro class resources construction including the micro class knowledge selection, teaching design and micro class recording. The author has explored the micro class in general in the course of application, and has provided some new thinking ways of this kind of curriculum construction and teaching reform.
\end{abstract}

\section{Introduction}

With the vigorous development of computer Internet plus, and the mutual penetration of information technology and traditional various disciplines, the cross use of different disciplines becomes more and more closely, the university computer foundation course is facing to the hitherto unknown challenge. Especially the micro class teaching mode gradually penetrated into the various disciplines teaching in universities, and the new teaching mode has important significance for the innovation on the teaching method of different specialties. The application of micro class in the basic computer teaching of universities non-computer majors can greatly improve the teaching efficiency and teaching effect of university computer foundation teaching [1]. This paper will explore the application and practice of the new teaching model about micro class in the university computer foundation course.

\section{Course Teaching Situation}

The university computer foundation course is a compulsory course for freshmen of non-computer major in applied undergraduate universities. The teaching purpose of this course is to enable students to master basic knowledge and basic skills of computer application, and the teaching software environment is Windows7+Office2010. The current teaching situation of this course is mainly shown as following.

The curriculum for freshmen which have their geographical differences and uneven educational level, often leads to uneven teaching of the course, and the differentiation of students' computer level is obvious, which is not conducive to the development of teachers' teaching.

For different regions, different majors and different levels of students, the current university computer basic teaching adopts unified theoretical teaching material and unified practice guidance. The teaching process of this course is still mainly centered on large class teaching and teacher teaching, and the teaching mode is still "centralized class and boarding experiment guidance". Therefore, this situation will lead to the two extremes of students' learning: some students will feel good and the basic computer teaching content is too simple, it will make some students feel boring and not practical, so as to reduce the students' learning initiative and enthusiasm; but the other students with poor computer base will feel that the teaching progress is too fast, and the content is complex and obscure, which will affect the teacher's class progress [2-3].

There is a difference between the computer teaching and the needs of the students and the social needs. The purpose of computer basic course education is to teach students to master basic skills of 
computer application. After learning computer related basic theories, students enhance their practical ability of commonly used software in computers, and they can flexibly use software to solve practical problems encountered in their work and study. However, they found in the teaching, many students in the computer after the teaching, they are not familiar with the software and the flexible application of skills and techniques and they couldn't efficiently solve problems independently. Thus, the difference exists between computer teaching and students' needs and social needs, and it is also a problem that we need to solve in the process of teaching [4].

\section{Application of Micro Class in the University Computer Foundation Teaching}

Renewing Teachers' Teaching Methods and Teaching Ideas. The biggest characteristic of the micro class is small, under normal circumstances, and the micro class time is within 10 minutes, start teaching in streamlining the short effective teaching time, to change the traditional teaching mode of computer basic course plays an important role. The traditional teaching time is 40 minutes. When teachers are teaching, they do not concentrate their time on a knowledge point. Most of the time, students are not fully absorbed. The application of micro lesson in college computer basic teaching is not only a way for teachers to transform teaching methods, but also an important strategy to improve students' interest in computer learning. First of all, micro class teaching belongs to the new teaching mode, fresh students, can attract the attention of students, and stimulate students' learning desire. Secondly, the micro class time is short, its application in the teaching of basic computer courses, it can let the students get knowledge in the relaxed environment, and enhance students' self-learning ability. Finally, when the students have interest in learning, learning objectives will be the new custom, some students will advance the teacher's teaching, with micro class teaching self-study to complete the next chapters. Thus it will improve students' computer application ability and practice ability.

Highlighting the Main Position of the Students. Computer classroom teaching is always based on teachers, while students are passively accepting knowledge, so it is difficult to develop students' autonomy and independence in computer knowledge learning. The use of micro class teaching mode can improve students' subjective status and improve their autonomous learning ability. Students are more likely to master the key points and difficulties of teaching, and further develop the students' divergent thinking ability. First of all, teachers in the curriculum teaching, has always been to establish a student-centered teaching consciousness, improve students' master of thought, carry out teaching activities is to enable students to master the ability of computer application; in addition, teachers in the teaching of computer, can use the micro teaching mode, play the initiative of students, create a good learning atmosphere, stimulate students' learning initiative, to enable students to gain more knowledge of computer. For example, the function of teaching in the application of Countif function of Excel, in the micro class teaching for 8 minutes, after studying the students "information workers" data statistics and analysis, the teacher asked the students to set the scene, demoed the problem-solving process, teachers of students are guided and encouraged, will make the entire classroom learning atmosphere and students learning enthusiasm, promote the development of students' individual ability [4, 5].

Choosing the Content Rationally and Broadening the Students' Ability. Micro class, as the name suggests, its main feature is "micro". Micro class is developed on the basis of traditional classroom teaching, which is very different from traditional classroom teaching. We should develop students' cognition ability to computers by using "tiny and meticulous" micro class, and develop students' computer application ability based on computer technology courses. When developing micro class activities, teachers should carefully select the contents of computer courses according to their learning level. They should not only show the key points and difficulties of college computer courses, but also conform to students' computer learning thinking. At the same time, teachers should take into account the coherence and independence of the micro class in the design of the content of the micro class. For example, in the animation is set on the PowerPoint, teachers can first use the micro class in 8 minutes on end, add animation settings effect options set operations, after the organization students independently complete the animation design of a PPT works in a certain period of time, and then improve the effect of classroom teaching and training students greatly the computer application level. 


\section{Micro class Resource Construction of the University Computer Foundation Course}

University computer foundation is a practical course, mainly needs student using computer software to solve problem, and it has loose connection of knowledge points. Therefore, it can separate key points and difficult contents into independent micro class contents, thus forms micro curriculum resources [5-7].

Selection of Knowledge Points in Micro Class. "Micro class" is the organic integration of teaching process and related resources based on teaching video as the main teaching method and the specific knowledge points. The length of the "micro class" is generally 5-8 minutes, the longest not more than 10 . Therefore, the construction of "micro lesson" should first divide the key points and difficult points in the teaching process of university computer basis according to the principle of "minimum granularity", that is, a learning object carrying a knowledge point, and then segment it into micro content. The contents of the course of university computer basis can be divided into five modules, which are theoretical application, Word basic operation, Excel basic operation, PowerPoint basic operation and network application. In the process of resource construction, we should start from the needs of learners, not only considering the independence of different micro class contents, but also considering the logical relationship of the whole knowledge module. Others, we organize each module contents in the form of point to surface. For example, the PowerPoint application, select text editing, template application, layout, animation and switching, show setting knowledge to explain, this is the "point"; at the same time, the introduction of the "surface" classroom case (graduation reply presentation), divided into two speak record. In the selection of "point", the principle of minimum granularity is followed, and the logical relationship between points is considered in the content of "face".

Micro Class Teaching Design. After defining the content of the construction of the course micro class, the next thing to do is the teaching design. The author takes the practical application as the main line and solves the problem as the guidance. The teaching method adopts the 6 teaching links: "introducing questions", "analyzing questions", "demonstrating cases", "summarizing and evaluating", "expanding cases" and "extending knowledge. Specific implementation follows the following principles: cutting into the topic quickly; giving clear clues and highlighting key contents; teachers' language is appropriateness, accuracy, logic and simplicity. Fig. 1 is the design of the teaching activities for the "SmartArt" Application in the basic PowerPoint operation.

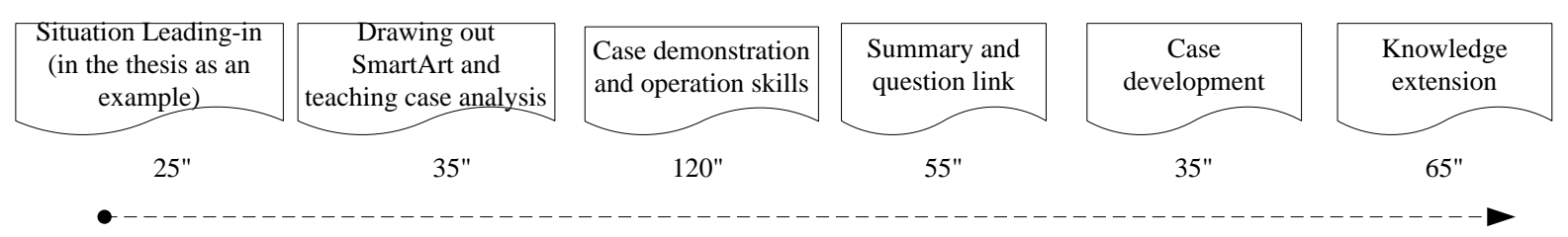

Figure 1. Micro class teaching design of SmartArt

Micro Class Recording and Editing. At present, the method of micro class recording screen recording software, video recording tool for recording, recording, recording room and special software production and IPAD recording. "University Computer Basis" is an operation oriented course. The nature of the content belongs to the operation demonstration class. So the recording software is mainly used to realize the recording of the micro lesson. We use Camtasia Studio 8 software to achieve screen recording. The size of the recording operation window can be set to $720 * 576(1280 * 720)$. After recording, we finish the video clips, and finally generate two formats of FLV and MP4 files. It is convenient for different terminals to access the resources smoothly after uploading the network. The operation window is adjusted to $720 * 576(1280 * 720)$, the purpose of which is to record a micro class that can be clearly played on all terminal devices, including mobile devices. 


\section{Conclusions}

The new teaching mode of micro class is rising, which is of great significance to improving the traditional teaching mode. The time of micro lesson to determine the content of micro lesson concentration, micro lesson concentration determines the single micro teaching goal, teaching model is a new kind of micro to the traditional classroom teaching is an important means to improve the basis of breakthrough, innovation of computer teaching, teaching quality. This requires teachers in the teaching materials, familiar with computer basic knowledge framework, clear teaching focus, understand the difficulty of teaching. Combing with the cognitive level of students in applied undergraduate colleges, the use of micro class aided computer teaching could provide an innovative idea for the practical operation and demonstration courses, and it could improve the teaching quality and teaching effect in general knowledge course. It also provides some suggestions for the teaching reform of the related courses in the current applied undergraduate colleges.

\section{Acknowledgements}

This work was supported by the first demonstration core curriculum construction project of "13-5" of Zhejiang University of Water Resources and Electric Power (Project No.44).

\section{References}

[1] Jian Ke, Liu Yuncheng,.. Reform and practice of university computer course teaching: taking city College of Dongguan University of Technology as an example [J]. Dongguan University of Technology, 2017 24(1): 120-124.

[2] Sun Min. Research on teaching content of University Computer Course Based on Computational Thinking in Applied Colleges and universities [J]. Journal of Higher Education, 2016 (21):60-61.

[3] Wang Yonggang. The application of micro class in the basic teaching of computer research [J]. Time Education, 2017 (7): 184.

[4] Ren Haiyan. The application of micro class in computer basic teaching [J]. Computer Knowledge and Technology, 2017 13(2): 139-140,145.

[5] Cai Youlan, Ning Jifeng. The application of micro class in the teaching of the basic course of computer application [J]. China Computer \& Communication, 2016, (1): 235-236.

[6] Tang Wenjie. Application of micro class in computer teaching [J]. Asia-Pacific Education, 2016, (9): 68-68.

[7] Bai Shibing. The discussion and practice of computer basic teaching in Applied Undergraduate Colleges under the background of general education [J]. Fu Jian Computer, 2016 (34):120. 